\title{
Gender Differences in Pragmatic Strageties of Disagreement in Chinese
}

\author{
YANG Yan \\ Faculty of Foreign Languages and Cultures \\ Kunming University of Science and Technology \\ Kunming, Yunnan, China \\ yangyanhch@163.com
}

\begin{abstract}
Compared with studies on speech acts of compliment, request and apologizing, researches on gender differences in disagreement in Chinese, by so far, have been found insufficient. Thus, this study sets out to examine gender differences in the selection of pragmatic strategies of disagreement with the purpose of explaining such differences. The study is based on the theoretical basis of speech act theory,Brown and Levinson's politeness theory and Gu's Chinese politeness maxims. The data are collected via Discourse Completion Tasks (DCT) and interviews. 100 subjects are selected from the sophomores in Southwest Jiaotong University. Gender differences in the choice of disagreement strategies are examined by t-test. The findings show that females are more likely to use mitigated strategies than males, and males tend to use aggravated strategies more frequently than females. Such differences indicate different gender psychology and gender identities in their socialization process.
\end{abstract}

Keywords-speech act; disagreement; gender difference; pragmatic strategy

\section{INTRODUCTION}

Since the early 1970s, prompted by the women's movement, research on language and gender has been receiving more attention from linguists. Earlier researches on gender differences mainly focused on phonology, morphology and syntax. With the development of speech act theory, empirical studies on speech acts which are regarded as the minimal meaningful units of discourse are flourishing. Disagreement is a commonly-occurred speech act in everyday life and is inherently a face-threatening act which undermines the solidarity and harmony between the interlocutors. Although there are a few studies on gender and strategy use in disagreement, most of them have been carried out in English-speaking countries. Relevant research on the Chinese language context is still in its infancy. The inadequacy of the investigation of gender and disagreement strategies gives stimulus to the author's writing of this paper. The present study attempts to answer the following questions:

- What is the overall tendency of disagreement strategy use between males and females? Do they differ?

- $\quad$ Do the mitigated and aggravated strategies use differ between male and females in relation to social status?

- $\quad$ Do the mitigated and aggravated strategies use differ between male and females in relation to social distance?
- Do the mitigated and aggravated strategies use differ between male and females in relation to sex of addressee?

The theories involved in this paper are: speech act theory [1], Brown and Levinson's politeness theory [2] and Gu's Chinese politeness maxims [3]. Discourse Completion Tasks (DCT) and interviews are employed to collect data. In the DCT, ten scenarios embedding three social factors (social status, social distance and sex of addressee) are designed. 100 subjects are selected from the sophomores in Southwest Jiaotong University. The classification of the disagreement strategies in the present study is based on the taxonomy established by Rees-Miller who categorizes disagreement strategies into three broad types: mitigated disagreement, disagreement not softened or strengthened and aggravated disagreement [4]. Yet in the pilot study of the instrument of this thesis, it has been found that the frequency of disagreement not softened or strengthened is almost none in our data of this study, it is excluded in the present study. Consequently, disagreement strategies in the present study are classified into two broad types: mitigated strategies and aggravated strategies. In terms of semantic formulae of mitigated and aggravated strategies, there is no available taxonomy which is appropriate for analyzing the data in the present study. So the author absorbs the results from the previous research of Muntigl \& Turnbull [5], Rees-Miller [4], Wang [6], Liu [7], and Liang [8], and revisions are made for the fulfillment of the purpose of the study. So the semantic formulae of mitigated strategies in the present study are further divided into Hedges, Questions; Positive Remarks and Expression of Gratitude plus Avoiding. On the other hand, the semantic formulae of the aggravated strategies are classified into Judgmental Vocabulary, Direct Disagreement and Rhetorical Questions.

The present study is conducive to the understanding of gender and language issues in Chinese context as well as the universality of language and gender. In addition, the study may be of help for those who are studying language and gender and the speech act of disagreement in Chinese, and it also shed light on the teaching of Chinese as a foreign language and cross-cultural communication.

\section{OVERALl StRATEGIES USE IN DISAGREEMENT}

The two types of strategies: mitigated strategies and aggravated strategies will be observed in terms of the overall situations, and a statistical analysis is performed to determine the significant differences across the two groups. 


\section{A. Mitigated versus Aggravated Strategies Use}

The obtained occurrences of each type of strategy used by the two groups are presented in Table 1.From it, we can observe that, on average, both male and females use more mitigated strategies when disagree with others. The proportion of mitigated strategies used by the two groups in overall situations amounts to $85 \%$ of the total number of strategies. Males was observed to utilize 3.55 times as many as mitigated strategies (78\%) versus aggravated strategies, whereas females was observed to utilize 11.39 times as many as mitigated strategies (92\%) versus aggravated strategies. Although both males and females use more mitigated strategies than aggravated strategies, the greater preference for mitigated strategies on the part of females should be noticed.

T-test was employed to examine the statistically significant differences across the two types of strategies for each group. The t-test analysis proves that there are statistically significant difference in the use of both aggravated strategies and mitigated strategies $(\mathrm{t}=6.20$, $\mathrm{P}=0.05$ ) between males and females.

TABLE I. Distribution Of Two TyPes Of Strategies

\begin{tabular}{|l|l|l|}
\hline \multicolumn{2}{|c|}{ Total occurrences of mitigated and aggravated strategies in } \\
overall situations
\end{tabular}

(Note: $\mathrm{M}$ refers to male; $\mathrm{F}$ refers to female.)

\section{1) Mitigated Strategy Use between Males and Females}

According to Brown and Levinson, disagreement is a face-threatening speech act [2]. Consequently, the mitigated strategies are preferred when expressing disagreement in order to enhance the solidarity and harmonious relationship between interlocutors. By adopting mitigated strategies when showing his/her opposite position, the speaker is attentive to the addressee's face needs and minimizes face threat to the addressee.

As Table 2 suggests, mitigated strategies utilized in the present study include: hedges, question; positive remarks, and expression of gratitude plus avoiding. We can find: the realization patterns of mitigated strategies by males are following this trend: Expression of Gratitude plus Avoiding>Positive remarks, Hedges, Question respectively. Females' realization patterns of mitigated strategies are: expression of gratitude plus avoiding>hedges, positive remarks, questions respectively.
TABLE II. DISTRIBUTION OF Mitigated StRATEGIES IN OVERALL SITUATIONS

\begin{tabular}{|c|c|c|}
\hline \multicolumn{3}{|c|}{$\begin{array}{c}\text { Total occurrences of every mitigated strategies in overal } \\
\text { situations }\end{array}$} \\
\hline \multirow{2}{*}{ Types } & \multicolumn{2}{|c|}{ Groups } \\
\hline & $\mathrm{M}$ & $\mathrm{F}$ \\
\hline Hedges & 81 & 86 \\
\hline Question & 76 & 71 \\
\hline Positive Remarks & 84 & 72 \\
\hline 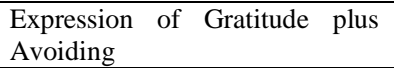 & 149 & 203 \\
\hline Total No. & 390 & 432 \\
\hline
\end{tabular}

As Lobov and Franshel argues that within conversation, participants may select to perform actions in either mitigated or modulated ways, or alternatively in aggravated or unmodulated ways [9]. As far as the speech act of disagreement is concerned, the speaker can either adopt various mitigated strategies to postpone the position of opposition with respect to the utterance articulated by prior speaker and soften his/her disagreement or immediately adopt aggravated strategies to put forward counter opinion in unmitigated fashion and aggravated his/her disagreement. It can be observed from table 3 that males use more direct disagreement than rhetorical question, judgmental vocabulary respectively when showing their disagreement towards others, and females use more rhetorical question than direct disagreement, judgmental vocabulary.

TABLE III. DISTRIBUTION OF AGGRAVATED STRATEGIES IN OVERALL SITUATIONS

\begin{tabular}{|l|l|l|}
\hline \multicolumn{2}{|c|}{ Total occurrences of every aggravated strategies in overall } \\
situations \\
\cline { 2 - 3 } Types & M & Groups \\
\hline \multirow{2}{*}{ Judgmental Vocabulary } & 30 & $\mathrm{~F}$ \\
\hline Direct Disagreement & 46 & 4 \\
\hline Rhetorical Question & 34 & 8 \\
\hline Total No. & 110 & 26 \\
\hline
\end{tabular}

\section{B. Disagreement Strategy Use in Relation to Social Status}

In this section, the second question of the present study "Do the mitigated and aggravated strategies use differ between males and females in relation to social status" will be answered.

\section{1) Mitigated Strategies versus Aggravated Strategies}

From the observation of Table 4 , we can find that both males and females use more mitigated strategies than aggravated strategies when express their disagreement to people who are in higher social status (teachers). To be more specific, males use 18.8 times as many as mitigated strategies (95\%) versus aggravated strategies. What is worthy noticing is that females are observed to utilize no aggravated strategies when disagreeing with their teachers. The statistical analysis of t-test indicates that Females use more mitigated strategies than males, and males employ more aggravated strategies than females when showing their opposite opinion to their teachers $(\mathrm{t}=2.49, \mathrm{p}=0.01<0.05)$.

Table 4 manifests that the preferred devices for both males and females to perform the speech act of disagreement 
to their equals are mitigated strategies rather than aggravated strategies. Males use 2.41 times as many as mitigated strategies $(71 \%)$ versus aggravated strategies. Females utilized 6.62 times as many as mitigated strategies (86\%) versus aggravated strategies. The statistical analysis of t-test reveals that females use more mitigated strategies than males $(\mathrm{t}=4.89, \mathrm{p}=0.05)$.

Table 4 also exhibits that both males and females select more mitigated strategies than aggravated strategies when show their disagreement to people who are in lower social status (students), to be more specific, Males use 4.88 times as many as mitigated strategies (83\%) versus aggravated strategies, and females use 93 times as many as mitigated strategies (99\%) versus aggravated strategies. A comparison of the two groups indicates that females use more mitigated strategies than males when disagreeing with people who are in lower positions, and the difference is statistically significant $(\mathrm{t}=4, \mathrm{p}=0.05)$.

In addition to what has been analyzed above, the comparison of the use of disagreement strategies with respect to social distance (higher, equal and lower) in each group shows that both males and females use more mitigated strategies to people who take an upper hand than to peoples who are in a lower position, and to their equals respectively.

TABLE IV. Distribution OF Mitigated AND AgGRavated STRATEGIES IN RELATION TO SOCIAL STATUS

\begin{tabular}{|l|l|l|l|l|}
\hline \multirow{2}{*}{$\begin{array}{c}\text { Addressee's } \\
\text { status }\end{array}$} & \multirow{2}{*}{ Group } & \multicolumn{2}{|c|}{ Types of strategies } & \multirow{2}{*}{ Total No. } \\
\cline { 3 - 5 } & & $\begin{array}{c}\text { Mitigated } \\
\text { strategy }\end{array}$ & $\begin{array}{c}\text { Aggravated } \\
\text { strategy }\end{array}$ & \\
\hline \multirow{2}{*}{ Higher } & $\mathrm{M}$ & 95 & 5 & 100 \\
\cline { 2 - 5 } & $\mathrm{F}$ & 94 & 0 & 94 \\
\hline \multirow{2}{*}{ Equal } & $\mathrm{M}$ & 70 & 30 & 100 \\
\cline { 2 - 5 } & $\mathrm{F}$ & 88 & 6 & 94 \\
\hline \multirow{2}{*}{ Lower } & $\mathrm{M}$ & 83 & 17 & 100 \\
\cline { 2 - 5 } & $\mathrm{F}$ & 93 & 1 & 94 \\
\hline
\end{tabular}

2) Semantic Formulas of Mitigated Strategies and Aggravated Strategies

The distribution of semantic formulas of mitigated strategies and aggravated strategies used by males and females in relation to social status are displayed in Table 5. The intra-group and inter-group comparison will be made in order to find out the differences and similarities in the use of each mitigated and aggravated strategy towards people who are in higher position, equals and those who are in a lower position.

As to the comparison of the use of semantic formulas of mitigated strategies by the two groups, the following properties stand out:

- When disagreeing with people who are in relatively higher position, the intra-group comparison shows that males use more Expression of Gratitude plus Avoiding (42\%) than Hedges (25\%), Positive Remark (22\%), and Question (10\%) respectively Females use more Expression of Gratitude plus Avoiding (43\%) than Hedges (26\%), Question (20\%), and Positive Remark (9\%) respectively. The inter-group comparison manifests that males use more positive remark than females to disagree with their teachers $(\mathrm{t}=2.38, \mathrm{p}=0.02<0.05)$.
- When disagreeing with people with equal social status, the intra-group comparison shows that both males and females use more Expression of Gratitude plus Avoiding $(36 \%, 48 \%)$ than Hedges $(23 \%, 22 \%)$, Question $(22 \%, 16 \%)$ ), and Positive Remark (17\%, $13 \%)$. The inter-group comparison indicates that females use more Expression of Gratitude plus Avoiding than males $(\mathrm{t}=2.55, \mathrm{p}=0.01<0.05)$.

- When disagreeing with people with lower social status, the intra-group comparison shows that males both males and females use more Expression of Gratitude $(37 \%, 46 \%)$ than Positive Remark (32\%, $33 \%)$, Question $(21 \%, 12 \%)$, Hedges $(8 \%, 7 \%)$. The inter-group comparison shows no difference in the use of each strategy between males and females.

As to the comparison of the use of semantic formulas of aggravated strategies by the two groups, the following properties stand out:

- Males are observed to use more semantic formulas of aggravated strategies than females when disagreeing with people with three levels of social status respectively than females do in analogous situation as Table 5 shows. As so salient and obvious the difference is, the statistical analysis is canceled.

- Both males and females use more Judgmental Vocabulary to their equals and people of lower social status than to people of higher position.

TABLE V. Distribution OF SEMANTIC Formulae OF Mitigated And Aggravated StRategies Used By Males AND FEMALES IN RELATION TO SOCIAL STATUS

\begin{tabular}{|l|l|l|l|l|l|l|l|l|l|}
\hline \multirow{2}{*}{$\begin{array}{c}\text { Address } \\
\text { ee's } \\
\text { status }\end{array}$} & \multirow{2}{*}{$\begin{array}{c}\text { Grou } \\
\mathbf{p}\end{array}$} & \multicolumn{6}{|c|}{ Types of strategies } & \multirow{2}{*}{$\begin{array}{c}\text { Total } \\
\text { No. }\end{array}$} \\
\cline { 3 - 11 } & & $\mathrm{H}$ & $\mathrm{Q}$ & $\mathrm{P}$ & $\mathrm{E}$ & $\mathrm{J}$ & $\mathrm{D}$ & $\mathrm{R}$ & \\
\hline \multirow{2}{*}{ Higher } & $\mathrm{M}$ & 24 & 1 & 21 & 40 & 0 & 4 & 1 & 100 \\
\cline { 2 - 11 } & $\mathrm{F}$ & 25 & 19 & 9 & 41 & 0 & 0 & 0 & 94 \\
\hline \multirow{2}{*}{ Equal } & $\mathrm{M}$ & 18 & 22 & 18 & 12 & 13 & 8 & 9 & 100 \\
\cline { 2 - 11 } & $\mathrm{F}$ & 18 & 21 & 17 & 32 & 1 & 0 & 5 & 94 \\
\hline \multirow{2}{*}{ Lower } & $\mathrm{M}$ & 7 & 18 & 27 & 31 & 7 & 4 & 6 & 100 \\
\cline { 2 - 11 } & $\mathrm{F}$ & 7 & 12 & 31 & 43 & 0 & 0 & 1 & 94 \\
\hline
\end{tabular}

(Notes: H stands for Hedges; Q stands for Question; P stands for Positive Remarks; E stands for Expression of Gratitude plus Avoiding; J stands for Judgmental Vocabulary; D stands for Direct Disagreement; R stands for Rhetorical Question)

\section{Strategy Use in Relation to Social Distance}

In the coming section the third research question "Do the frequencies of mitigated and aggravated strategies use differ between males and females in relation to social distance" will be addressed from two angles: frequency of mitigated strategies versus aggravated strategies and frequency of semantic formulas of mitigated strategies and aggravated strategies.

1) Mitigated Strategies versus Aggravated Strategies

Table 6 exhibits the distribution of mitigated and aggravated strategies used by males and females in terms of three levels of social distance: acquaintance (classmate in the present study); friend and stranger.

It can be learn from Table 6 that males use 2.33 times as much as mitigated strategies $(70 \%)$ to aggravated strategies 
when show their oppositional opinion towards their acquaintance. Females use much more mitigated strategies (94\%) than aggravated strategies in the same situation (14.7 times as much as mitigated strategies to aggravated strategies). The comparison across the two groups shows that females use more mitigated strategies than males when disagreeing with their acquaintances $(t=3.94, \mathrm{p}=0<0.05)$.

As reflected in Table 6, when disagreeing with their friends, males use 1.1 times as much as mitigated strategies $(52 \%)$ to aggravated strategies, and the difference is marginal. Females are observed to use 2.35 as much as mitigated strategies (70\%) to aggravated strategies in the analogous situation. The inter-group comparison indicates that females use more mitigated strategies than males and males use more aggravated strategies than females when showing their contrary opinion to their friends. The result of t-test manifests the difference is statistically significant $(\mathrm{t}=2.63, \mathrm{p}=0.01<0.05)$.

Through the observation of Table 6 , we can see that males use 9 times as much as mitigated strategies (90\%) to aggravated strategies to show their disagreement towards strangers, and what should be noticed is that females use as much as 33 times mitigated strategies (96\%) to aggravated ones. The comparison across the two groups shows that there is no statistically significant difference in the use of mitigated strategies and aggravated strategies by males and females to strangers $(\mathrm{t}=1.93, \mathrm{p}=0.05)$.

Except for the analysis mentioned above, the comparison of the use of the two types of strategies to three-level socials distance within each group shows that both males and females use more mitigated strategies to strangers than to acquaintance and friends respectively.

TABLE VI. DISTRIBUTION OF MITIGATED AND AGGRAVATED STRATEGIES USED BY MALES AND FEMALES IN RELATION TO SOCIAL DISTANCE

\begin{tabular}{|l|l|l|l|l|}
\hline \multirow{2}{*}{$\begin{array}{c}\text { Social } \\
\text { distance }\end{array}$} & \multirow{2}{*}{ Group } & \multicolumn{2}{|c|}{ Types of strategies } & \multirow{2}{*}{$\begin{array}{c}\text { Total } \\
\text { No. }\end{array}$} \\
\cline { 3 - 4 } & & $\begin{array}{c}\text { Mitigated } \\
\text { strategy }\end{array}$ & $\begin{array}{c}\text { Aggravated } \\
\text { strategy }\end{array}$ & \\
\hline \multirow{2}{*}{ Acquaintance } & $\mathrm{M}$ & 70 & 30 & 100 \\
\cline { 2 - 4 } & $\mathrm{F}$ & 88 & 6 & 94 \\
\hline \multirow{2}{*}{ Friend } & $\mathrm{M}$ & 52 & 48 & 100 \\
\cline { 2 - 4 } & $\mathrm{F}$ & 66 & 28 & 94 \\
\hline \multirow{2}{*}{ Stranger } & $\mathrm{M}$ & 90 & 10 & 100 \\
\cline { 2 - 4 } & $\mathrm{F}$ & 91 & 3 & 94 \\
\hline
\end{tabular}

2) Semantic Formulas of Mitigated Strategies and Aggravated Strategies

Table 7 displays the distribution of semantic formulae of mitigated and aggravated strategies used by males and females in terms of three-level of social distance (acquaintance; friend and stranger). In the following section, the inter-group and intra-group comparison will be made in order to find out the differences and similarities in the use of each mitigated and aggravated strategy by the two groups.

As to the comparison of the use of semantic formulae of mitigated strategies by the two groups, the following conclusions are obtained:

- When disagreeing with acquaintances, males use more Questions $(22 \%)$ than Hedges (18\%); Positive Remark (18\%) and Expression of Gratitude plus
Avoiding (12\%) respectively. As Table 7 suggests, females use more Expression of Gratitude (32\%) than Question (22\%); Hedges (19\%) and Positive Remark (18\%) respectively. The inter-group comparison indicates that females use more Expression of Gratitude plus Avoiding than males, and the result is statistically significant $(t=3.72$ $\mathrm{p}=0<0.05)$.

- When disagreeing with their friends, males are observed to use more Question (16\%) than Expression of Gratitude plus Avoiding (15\%); Hedges (13\%) and Positive Remarks (8\%) respectively while females use more Expression of Gratitude plus Avoiding (32\%) than Hedges (22\%); Positive Remark (8\%) and Question $(7 \%)$. The intergroup comparison shows that females use more Expression of Gratitude plus Avoiding than males $(\mathrm{t}=2.35 \mathrm{p}=0.02<0.05)$.

- When disagreeing with strangers, from Table 7 we can know that males use much more Expression of Gratitude plus Avoiding (51\%) than Hedges (19\%); Question (10\%) and Positive Remark (10\%) respectively. Similar to the pattern of males', females also use more Expression of Gratitude plus Avoiding (61\%) than Hedges (16\%); Question (13\%) and Positive Remark (7\%). The inter-group reveals that there are no differences in the use of the four types of semantic formulae of mitigated strategies by the two groups.

As to the comparison of the use of semantic formulae of aggravated strategies by the two groups, the following conclusions are obtained:

- The most frequently used semantic formula of aggravated strategy by males when show their disagreement towards their acquaintances, friends and strangers is Judgmental vocabulary. However females use Rhetorical Question more frequently than other semantic formulae.

- Males use more Judgmental Vocabulary and Direct disagreement than females when disagreeing with acquaintances $\quad(\mathrm{t}=3.33 \quad \mathrm{p}=0.001<0.05), \quad$ friends $(\mathrm{t}=2.75 \mathrm{p}=0.006<0.05 ; \mathrm{t}=2.40 \quad \mathrm{p}=0.02<0.05)$ and strangers than females.

TABLE VII. DISTRIBUTION OF SEMANTIC FORMULAE OF MITIGATED AND AGGRAVATED STRATEGIES USED BY MALES AND FEMALES IN RELATION TO SOCIAL DISTANCE

\begin{tabular}{|c|c|c|c|c|c|c|c|c|c|}
\hline \multirow{3}{*}{$\begin{array}{c}\text { Social } \\
\text { distance }\end{array}$} & \multirow{3}{*}{$\begin{array}{l}\text { Gro } \\
\text {-up }\end{array}$} & \multicolumn{7}{|c|}{ Types of strategies } & \multirow{3}{*}{$\begin{array}{c}\text { Tot } \\
\text { al } \\
\text { No. }\end{array}$} \\
\hline & & \multicolumn{5}{|c|}{\begin{tabular}{l|l} 
Mitigated \\
strategies
\end{tabular}} & \multicolumn{2}{|c|}{$\begin{array}{l}\text { Aggravated } \\
\text { strategies }\end{array}$} & \\
\hline & & $\mathrm{H}$ & Q & $P$ & $\mathrm{E}$ & $\mathrm{J}$ & D & $\mathrm{R}$ & \\
\hline \multirow{2}{*}{$\begin{array}{l}\text { Acquain } \\
\text { tance }\end{array}$} & $\mathrm{M}$ & 18 & 22 & 18 & 12 & 13 & 8 & 9 & 100 \\
\hline & $\mathrm{F}$ & 18 & 21 & 17 & 32 & 1 & 0 & 5 & 94 \\
\hline \multirow{2}{*}{ Friend } & $M$ & 13 & 16 & 8 & 15 & 21 & 13 & 14 & 100 \\
\hline & $\mathrm{F}$ & 12 & 7 & 8 & 30 & 7 & 4 & 17 & 94 \\
\hline \multirow{2}{*}{ Stranger } & $\mathrm{M}$ & 19 & 10 & 10 & 51 & 4 & 2 & 4 & 100 \\
\hline & $\mathrm{F}$ & 15 & 12 & 7 & 57 & 0 & 0 & 3 & 94 \\
\hline
\end{tabular}




\section{Strategy Use in Relation to Sex of Addressee}

In this part, the last research question of the study "Do the mitigated and aggravated strategies use differ between males and females in relation to sex of addressee" will be answered. As mentioned before, it is predictable that females would use more mitigated strategies than males, so we divide the research question into two sub-questions: frequency of mitigated strategies versus aggravated strategies and frequency of semantic formulae of mitigated and aggravated strategies, and the two sub-questions will be revolved respectively in the forthcoming section.

1) Mitigated Strategies versus Aggravated Strategies

Through the observation of Table 8 , we can find that both males and females use more mitigated strategies aggravated strategies when they have to disagree with males. To be more specific, males are observed to use 2.38 times as much as mitigated strategies (70\%) to aggravated strategies and females use 7.7 times as much as mitigated strategies (89\%) to aggravated strategies when show their disagreement to males. The statistical analysis of t-test reveals that females use more mitigated strategies than males when the sex of the addressee is male $(\mathrm{t}=5.07 \mathrm{p}=5.85 \mathrm{E}-07)$.

When disagreeing with females, males are observed to use 5.94 as much as mitigated strategies (86\%) to aggravated strategies and females utilize 20.36 times as much as mitigated strategies (95\%) to aggravated strategies. The statistical analysis of t-test reveals that females use more mitigated strategies than males when show their oppositional stance to females $(\mathrm{t}=3.71, \mathrm{p}=0)$.

Besides the comparison mentioned above, It is worth noting that, as reflected in Table 8, both males and females use more mitigated strategies to females $(86 \%, 95 \%$ respectively) than to males $(70 \%, 89 \%$ respectively).

TABLE VIII. DISTRIBUTION OF MITIGATED AND AGGRAVATED STRATEGIES IN RELATION TO SEX OF ADDRESSEE

\begin{tabular}{|l|l|l|l|l|}
\hline \multirow{2}{*}{$\begin{array}{c}\text { Sex of } \\
\text { addressee }\end{array}$} & \multirow{2}{*}{ Group } & \multicolumn{2}{|c|}{ Types of strategies } & \multirow{2}{*}{$\begin{array}{c}\text { Total } \\
\text { No. }\end{array}$} \\
\cline { 3 - 4 } & & $\begin{array}{c}\text { Mitigated } \\
\text { strategy }\end{array}$ & $\begin{array}{c}\text { Aggravated } \\
\text { strategy }\end{array}$ & \\
\hline \multirow{2}{*}{ Male } & $\mathrm{M}$ & 176 & 74 & 250 \\
\cline { 2 - 4 } & $\mathrm{F}$ & 208 & 27 & 235 \\
\hline \multirow{2}{*}{ Female } & $\mathrm{M}$ & 214 & 36 & 250 \\
\cline { 2 - 4 } & $\mathrm{F}$ & 224 & 11 & 235 \\
\hline
\end{tabular}

2) Semantic Formulas of Mitigated Strategies and Aggravated Strategies

Table 9 exhibits the distribution of semantic formulae of mitigated strategies and aggravated strategies used by males and females in terms of two-level of sex of addressee: males and females.

As far as the comparison of semantic formulae of mitigated strategies are concerned, both males and females use more Expression of Gratitude plus Avoiding (24\%, 41\%) than Hedges $(20 \%, 21 \%)$, Positive Remark $(18 \%, 17 \%)$ and
Question (8\%, 8\%) respectively when show their disagreement to male addressee. When disagreeing with female addressee, males are observed to use more Expression of Gratitude plus Avoiding (35\%) than Question (22\%), Positive Remark (16\%) and Hedges (13\%) respectively, and females use more Expression of Gratitude plus Avoiding (45\%) than Question (21\%), Hedges (16\%) and Positive Remark (13\%).

The inter-group comparison of the frequency of the use of semantic formula of mitigated strategies showed that females use more Expression of Gratitude plus Avoiding than males when disagree with both males $(t=4, p=0.05)$ and females addressee $(\mathrm{t}=2.13, \mathrm{p}=0.05)$.

As far as the comparison of semantic formulae of aggravated strategies are concerned, the most frequently used semantic formula by males is Direct Disagreement (45\%) compared with the other semantic formulae of aggravated strategies when show their disagreement to male and females addressee. However females are observed to use more Rhetorical Question (55\%) than other aggravated strategies when they have to disagree with male and female addressee.

The inter-group comparison of the frequency of the use of semantic formulae of aggravated strategies indicates that males use more Judgmental Vocabulary $(\mathrm{t}=3.91, \mathrm{p}=0.05)$, Direct Disagreement $(\mathrm{t}=6.4, \mathrm{p}=0.05)$ and Rhetorical Question $(\mathrm{t}=4.4, \mathrm{p}=0.05)$ than females when both disagree with males and females.

TABLE IX. DISTRIBUTION OF SEMANTIC FORMULAE OF MITIGATED AND AGGRAVATED STRATEGIES IN RELATION TO SEX OF ADDRESSEE

\begin{tabular}{|c|c|c|c|c|c|c|c|c|c|}
\hline \multirow{3}{*}{$\begin{array}{c}\text { Types of } \\
\text { addressee }\end{array}$} & \multirow{3}{*}{ Group } & \multicolumn{7}{|c|}{ Types of strategies } & \multirow{3}{*}{$\begin{array}{l}\text { Total } \\
\text { No. }\end{array}$} \\
\hline & & \multicolumn{4}{|c|}{ Mitigated strategies } & \multicolumn{3}{|c|}{\begin{tabular}{|c|}
$\begin{array}{c}\text { Aggravated } \\
\text { strategies }\end{array}$ \\
\end{tabular}} & \\
\hline & & $\mathrm{H}$ & Q & $\mathrm{P}$ & E & $\mathrm{J}$ & $\mathrm{D}$ & $\mathrm{R}$ & \\
\hline \multirow{2}{*}{ Male } & M & 49 & 22 & 44 & 61 & 18 & 33 & 23 & 250 \\
\hline & $F$ & 49 & 21 & 41 & 97 & 2 & 1 & 3 & 235 \\
\hline \multirow{2}{*}{ Female } & M & 32 & 54 & 40 & 88 & 12 & 13 & 11 & 250 \\
\hline & $F$ & 37 & 50 & 31 & 106 & 2 & 3 & 6 & 235 \\
\hline
\end{tabular}

\section{CONCLUSION}

The present study explores the gender differences in disagreement behavior from a pragmatic point of view. The findings of this study provide an empirical basis for understanding of the speech act of disagreement from Chinese context. By a thorough analysis of 970 disagreement data collected by means of Multiple Choices, we have found that there are gender differences in disagreement realization strategies with the Chinese Language. The major findings are as follows:

- As for gender differences in the use of disagreement strategies in overall situations, the present study indicates that both males and females use more mitigated strategies than aggravated strategies when 
show their disagreement towards others. Females are observed to use more mitigated strategies and less aggravated strategies than males. In examining gender differences in the choice of semantic formulae of mitigated and aggravated strategies, females in the present study tend to choose more Expression of Gratitude plus Avoiding than males, and males tend to choose more Direct Disagreement, Judgmental Vocabulary and Rhetorical Question than females.

- As for gender differences in the use of disagreement strategies in relation to social status, the present study indicates that both males and females use more mitigated strategies to people of higher position than to people who are in lower status and to their equals respectively. Females are found to use more mitigated strategies than males regardless of social status. In examining gender differences in the selection of semantic formulae of mitigated and aggravated strategies, males are observed to use more Positive Remark than females when disagree with people who take an upper hand and females use more Expression of Gratitude Plus Avoiding than males when show their contrary opinion to people of lower position and to their equals. Besides, males use more Judgmental Vocabulary, Direct Disagreement and Rhetorical Question than females in terms of three levels of social status.

- As for gender differences in the use of disagreement strategies in relation to social distance, the present study shows that both males and females use more mitigated strategies to strangers than to acquaintances and friends respectively. Females are found to use more mitigated strategies than males to their acquaintances and friends. In examining gender differences in the choice of the choice of semantic formulae of mitigated and aggravated strategies, Females use more Expression of Gratitude plus Avoiding than males when disagree with acquaintances and friends, while males use more Judgmental vocabulary and Direct Disagreement than females when show their disagreement towards acquaintances and friends.
- As for gender differences in the use of disagreement strategies in relation to sex of addressee, the present study show that both males and females use more mitigated strategies to females than to males and females are found to use more mitigated strategies and less aggravated regardless of sex of addressee than males. In examining gender differences in the selection of semantic formulae of mitigated strategies and aggravated strategies, females are observed to use more Expression of Gratitude plus Avoiding than males regardless of sex of addressee, and males tend to use more Judgmental Vocabulary, Direct Disagreement and Rhetorical Question than females when disagree with both women and men.

In addition, the present study discusses the quantitative findings within the framework of Brown and Levinson's politeness theory and $\mathrm{Gu}$ Yueguo's Chinese politeness maxims. The findings in the present study is consistent with Holmes' view that women are more tentative to the face needs of addressee and are more polite than men [9].

\section{REFERENCES}

[1] J.Searle, What is a speech act? In Steven, D. (ed.) A Reader. New York: Oxford University Press, 1965.

[2] P. Brown, and S. Levinson, "Politeness: Some Universals in Language Usage". Cambridge: Cambridge University Press, 1987.

[3] Y. G. Gu, "Politeness phenomena in modern Chinese". Journal of Pragmatics. Vol.14, 1990, pp.237-257.

[4] R. Miller, "Power, severity and context in disagreement". Journal of Pragmatics. Vol.32, 2000, pp.1087 -1111.

[5] Muntigl, P. and Turnbull, W. "Conversational structure and facework in arguing". Journal of Pragmatics. Vol.29, 1998, pp.225256.

[6] Wang, W. M. A study on politeness strategies of disagreement in Chinese. Unpublished MA thesis, Shandong University, 2006.

[7] Liu, S. Pragmatic strategies and power relations in disagreement. Unpublished PhD thesis, Arizona University, 2004.

[8] Liang, G. D. "A contrastive study on disagreement strategies between American English and Mandarin Chinese". Electronic Resources in Southwest Jiaotong University library,2003.

[9] Holmes, J. "Paying compliments: a sex-preferential positive politeness strategy". Journal of Pragmatics. Vol.30, 1988, pp.3-1 